\title{
A Mobile Health App for Premarital Related Word Advice (AmeeSehat): Usability and Usefulness Evaluation Study
}

\author{
Zulvi Wiyanti*, Fadil Oenzil, Masrul Masrul, Defriman Djafri \\ Department of Public Health Sciences, Faculty of Medicine, Andalas University, West Sumatera, Indonesia
}

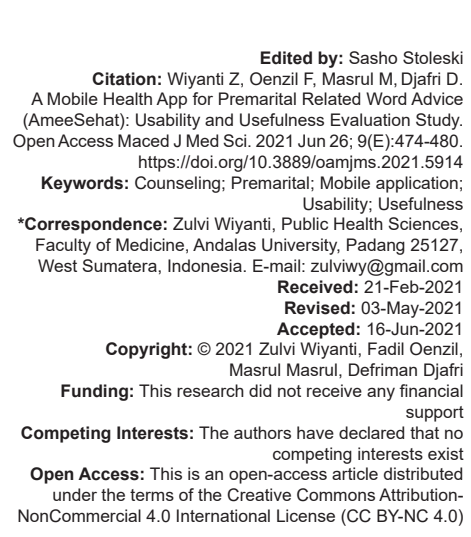

\section{Introduction}

Marriage is seen as a crucial predictor for determining the human physical and mental wellbeing [1]. There is definitely a need to explore the phenomenon of marriage and young people's approaches to marriage in order to promote healthy marriage in society [2], [3], [4]. Nevertheless, study indicates that more and more marriages (24\%) start at the lower satisfaction levels, which are more vulnerable to divorce [5]. In Indonesia, in the past 3 years, more than 1100 divorces, caused by domestic violence and financial problems, have been recorded daily across Indonesia [6]. To be ready for getting married, the individual must have the three aspects of maturity, commitment, and sufficient information [7]. It would, therefore, seem important to prepare young people for a successful marriage [8].

Premarital counseling demonstrates promising approach for enhancing interaction between couples and to prevent deterioration in the well-being of relationships [9]. Premarital counseling is a specific counseling to offer married people the opportunity to explore themselves and to evaluate the process. It also offers people entering marriage to discuss any situational issues that are important to their relationship [10], [11]. Premarital counseling has become one of the most effective ways to avoid inherited illnesses, congenital defects and genetic disorders [12], [13]. The delivery of high-quality premarital counseling programs is thus so essential to the healthcare delivery system. The World Health Organization has thus emphasized the significance of such services.

The premarital counseling program has been mandated and implemented in several countries such as Saudi Arabia and Malaysia under the policy different policy [14], [15]. For instance, in Saudi Arabia, the implementation of premarital counseling is focused on reproductive and sexual health, as well as screening for genetic disorders, and after completing premarital counseling the couples will be given a certificate [14]. Meanwhile, premarital counseling in Malaysia is conducted by private institutions (NGOs) known as the 
Pre-Marriage Course [15]. The contents of the course consist of religious training, family management, and overcoming family problems. Participants who have completed premarital counseling will receive a certificate as a permissibility requirement for getting married [15].

In Indonesia, premarital counseling is implemented in a pre-marriage course, which is held at the Office of Religious Affairs in collaboration with the Agency of Marriage Advisory, Counseling, and Preservation [16]. The curriculum of the pre-marriage course is designed by the Ministry of Religious Affairs. The course materials are divided into three groups, namely, the basic group, the core group, and the support group [17]. From further analysis, the largest proportion of the curriculum remains focused on providing knowledge about how to have happy marriage according to religious demands and social norms, while very little deals with health information [18]. The results of a study by Oktalia at two sub-district health centers in East Jakarta found that most of the couples of reproductive ages did not have the readiness to deal with pregnancy, with $64.6 \%$ of the total respondents [19]. Married couples with limited health knowledge often lack understanding or have misinformation about the body. They may not know the appropriate gestational age, the dangers of smoking, the dangers of hypertension, and the importance of having health insurance [19]. This shows that pre-married couples have not been targeted in the Healthy Indonesia Program with a family approach.

Mobile health (mHealth) apps may provide an appropriate solution to this issue, as many potential brides and grooms are frequent users of internet or web-based health info [20]. mHealth means using the smartphones to obtain information for healthy marriage, to increase their understanding of unhealthy habits in the family and family-related problems [21]. However, there is generally limited research of the efficacy of the mHealth app [22], [23]. In addition, little data were available on the effective methods or strategies to establish this mHealth [24]. The user's intention to develop apps should also be taken into account, including usability and usefulness [25]. Various usability assessment methods can measure problems in user involvement to develop more effective and useful of mHealth applications. Thus, a usability evaluation tests the human contact with a computer to recognize those factors that could be reinforced [22]. In an iterative approach, the schematic design is required to incorporate each product related to health better with the background of the consumer. In this iterative sequence of the health-care industry, usability evaluation is especially important as it may have adverse effects that are poorly designed and accessible to mHealth [24]. It is also recommended that usability evaluation be implemented during the mobile device development and testing phase [26].

In this study, we developed the mHealth Solution (AmeeSehat App) app to provide information and advice on healthy marriages. The content of the AmeeSehat App is developed based on the theory of social cognitive learning [27]. In this research, think aloud (TA) methods were selected to test the usability of the AmeeSehat app to expound the cognitive processes of users through their engagement with the application and to cause problems for user involvement. The AmeeSehat App was also tested by inviting three experts in informational technology. The TA method allows users to communicate when they conduct or complete a task (i.e. verbalize their thoughts, how they communicate with the app), which could lead to user interaction problems [28]. The goal of the TA is to help people understand how the AmeeSehat App works (their conceptual model) and how participants believe or think. Discrepancies between the users' conceptual model of an app and the creation of the app would have a significant effect on its usability and hence on its operational use. Therefore, this research aimed to measure the usability and usefulness of the AmeeSehat App as interpreted by prospective end users.

\section{Methods}

\section{Study design overview}

This study employed an exploratory mixed method design to examine the usability and usefulness of the AmeeSehat App with end-users. The mixed method approach enables the results to be triangulated using qualitative and quantitative methods. Qualitative assessment was carried out using the "TA" method with the help of a theme guide containing questions about usability and usefulness [29]. The retrospective TA technique has been selected to characterize the real use and focus on solving any unanticipated navigability real world problems contexts for users, rather than the forward thought-aloud method [29]. A questionnaire has also been used to quantitatively assess the usefulness and usability of AmeeSehat.

This research was carried out in one of the public-health centers in East Jakarta, Indonesia, with the future bride and bride. The inclusion criteria included future brides and grooms who have a mobile phone and who are able to interact in Bahasa Indonesia. Participant enrollment continued until a total of ten females and males' future bride and groom agreed to engage in and assess the TA app; this would be their first experience using the AmeeSehat App. Five experts review was also conducted to assess the content, performance, usefulness, integrity, feedback, continuity, shape, and terminology of the AmeeSehat App. Experts are asked to rate 0 (not very good) and 1 (good) for each point of assessment. 


\section{The AmeeSehat App (beta testing version)}

The AmeeSehat app (Bahasa) has been developed from any form of mobile browser as a mobilebased app with an asynchronous interface for Android use. The AmeeSehat app requires the user to create an account to get access to its content. A user must complete a list of questions regarding their marriage intentions and readiness (Figure 1). After completing this survey, the user will be directed to the home page of the app, from where they can browse all the information related to healthy marriage for premarital couples.

\section{Questionnaires on usability and} usefulness

The system usability scale (SUS) 10-item questionnaire was provided to the participants after the TA test was completed to assess the perceived usability of the AmeeSehat App [29]. The SUS had to score from 1 (strongly dissatisfied) to 5 (strongly agreed) to show the degree to which they agreed. In the current study, the content validity index of SUS was 0.68 and the Cronbach' Alpha was 0.71 . The usability of problems was calculated by the Nielsen severity scale [28]. The Nielsen severity scale is a rating scale of $0-4$ that makes it possible to recognize existing problems that need to be revised in the development process. In the current study, the content validity index of Nielsen severity scale was 0.71 and the Cronbach' Alpha was 0.78. The usefulness of the AmeeSehat App was assessed using a tool to evaluate an improvement in healthy family knowledge, attitude, and intention, and readiness to marry.

\section{Procedure and data analysis}

This study was approved by the Affiliated University Research Ethics Committee (E321/III/ ETIK/2019). Each participant was told that the researchers were mainly interested in the performance of the application and that the participant would only be interfered with providing the new assignment and allowing participants to continue speaking for not more than $5 \mathrm{~s}$ to silence [28]. Practical exercises about how to TA started with participants. In total, five tasks were performed by a participant based on the main objective of the app, namely, download, install, create account, filled the questionnaire, and read material. Tasks have been created in collaboration with the creator and project of the AmeeSehat app. TA sessions were videocaptured, evaluated, and transcribed into textual scripts by two researchers. The text stated by the participant to provide information about the effectiveness and effectiveness of the participants in performing tasks has been included in each TA meeting report. To examine the usability issues of participants in detail, we
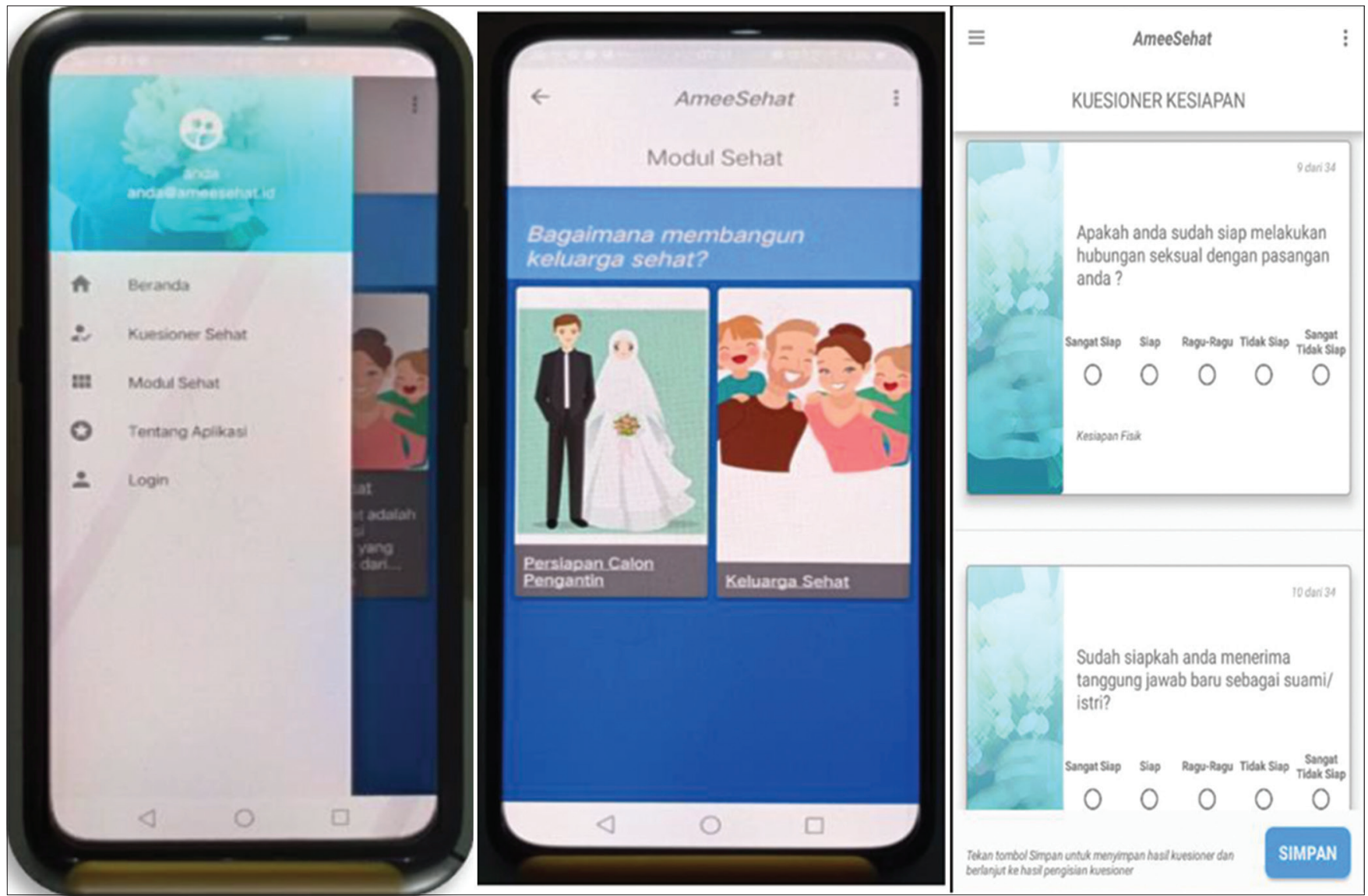

Figure 1: Examples of screenshots of AmeeSehat App 
performed a thematic analysis. We have extensively analyzed 2 TA meetings to establish a raw coding (first cycle). The usability challenges encountered by the participants were then clearly summarized. Finally, we analyzed and compiled the resulting codes to define key data themes (second cycle).

Once completed, users were requested to reply to a post-intervention questionnaire containing validated ten-question SUS [29], [30] and usefulness questions, including knowledge, attitudes, intention, and marriage readiness. All data were handled and analyzed using IBM SPSS Statistics version 21 for the quantitative data. First, each participant's SUS score and an average SUS score were determined for all participants. The SUS score has been interpreted using a descriptor rating scale developed by Bangor [31]. The usefulness questions were analyzed using descriptive statistics (percentage of yes). The pre- and post-intervention score was compared with the paired t-test for knowledge, attitude, intention, and marriage readiness.

\section{Results}

\section{Participant characteristics}

TA sessions with participants ( $n=10$ final users and three experts) and quantitative assessment with 60 participants were held. All participants used a mobile phone that had an Android operating system. The end user aged ranged from 24 to 30 years. All of them were employees and $50 \%$ graduated from bachelor's degree.

\section{Qualitative evaluation}

The participants reported the AmeeSehat app useful as they were able to learn more about healthy marriage and to do so to improve their health and marriage readiness. The AmeeSehat app contains data that were never known before.

"I like everything, how to prepare for your healthy family, wherever you are (in health terms), and what to do to improve it.". (P02)

"With these applications, people know what marriage readiness is relevant and have to be supported by pre-marital advice." (P01)

One participant said that using the AmeeSehat app would contribute to healthcare:

"AmeeSehat app is simple to use, could also give more understanding as a stimulator for healthcare and education via applications, with exception of people who receive nothing and will not do anything about their health." (P07).

Future bride and groom also felt it was convenient to use AmeeSehat app.
"We've got limited time for reading and learning. With this, at any place, we can learn many things, we can have the data and what we can do to improve health" (P06).

One participant mentioned the problem that after using it once, users may not use the AmeeSehat app again.

"It's nice. Will I be using the app? Yeah sure. But I will continue to use it repeatedly afterwards, it remains a question mark, executing their fresh content" (P10).

\section{Quantitative evaluation}

Experts and end users assessed the usability and usefulness of AmeeSehat App. Approximately three experts provided scores ranging from 0.50 to 0.88 (indicating goof performance and quality of AmeeSehat App), with the lowest score on performance quality (Mean=0.50, $S D=0.12$ ) and the highest score on integrity $($ Mean=0.88, SD=0.07) $($ Table 1).

Table 1: Quantitative evaluation after using the AmeeSehat App from experts

\begin{tabular}{ll}
\hline Variables & Mean \pm SD \\
\hline Contents quality & $0.60 \pm 0.08$ \\
Performance quality & $0.50 \pm 0.12$ \\
Usefulness & $0.70 \pm 0.18$ \\
App's integrity & $0.88 \pm 0.07$ \\
Users feedback & $0.61 \pm 0.05$ \\
Continuity & $0.73 \pm 0.10$ \\
Apps's shape & $0.57 \pm 0.11$ \\
Terminology & $0.67 \pm 0.19$ \\
\hline
\end{tabular}

About 60 end users responded to the postintervention questionnaire. Table 2 provides a summary of the most severe usability problems. The SUS score obtained (mean=78.4, SD=6.83) suggested that the AmeeSehat app achieved good usability [31]. None of the participants experienced (severe) problems with usability. Only one usability problems have been reported with a severity of 3 (major), that is, terminology comprehension issues.

Table 2: Overview of severe usability problems per main problem type $(n=60)$

\begin{tabular}{lll}
\hline Usability problem & Frequency & Severity \\
\hline Unclear buttons & 10 & $2-3$ \\
Functionality with layout & 35 & 2 \\
Terminology interpretation problems & 40 & 3 \\
Finding and understanding advice & 42 & 2 \\
\hline
\end{tabular}

Table 3 shows details of the quantitative assessment pre-post-intervention. Participants had a better understanding of a healthy family, a positive attitude toward a healthy marriage, a better intention toward a healthy family, and a more ready marriage.

Table 3: Quantitative evaluation after using the AmeeSehat App from end users $(n=60)$

\begin{tabular}{ll}
\hline Variables & Mean (SD) \\
\hline System usability scale score & $78.4 \pm 6.83$ \\
Understand more about healthy family & $58.5 \pm 6.95$ \\
Had a favorable attitude towards healthy family & $45.9 \pm 4.89$ \\
Had more intention towards healthy family & $72.7 \pm 5.38$ \\
Readiness to marriage & $40.2 \pm 4.89$ \\
Will recommend AmeeSehat App to others, $\mathrm{n}(\%)$ & $56(93.3)$ \\
\hline
\end{tabular}


Almost all participants would have recommended the AmeeSehat app to others.

The mean score of knowledge was significantly increased after intervention from $45.80 \pm 4.329$ to $58.55 \pm 6.951(p=0.000)$. Then, the mean score for attitude, intention, and marriage readiness was significant increased with $p<0.001$ (Table 4).

Table 4: Quantitative evaluation after using the AmeeSehat App from end users $(n=60)$

\begin{tabular}{llll}
\hline Variables & $\begin{array}{l}\text { Pre-test } \\
\text { Mean } \pm \text { SD }\end{array}$ & $\begin{array}{l}\text { Post-test } \\
\text { Mean } \pm \text { SD }\end{array}$ & p-value \\
\hline Knowledge & $45.80 \pm 4.329$ & $58.55 \pm 6.951$ & 0.000 \\
Attitude & $40.37 \pm 4.669$ & $45.93 \pm 4.892$ & 0.000 \\
Intention & $59.00 \pm 7.197$ & $72.70 \pm 5.381$ & 0.000 \\
Marriage readiness & $34.98 \pm 3.347$ & $40.22 \pm 4.737$ & 0.000 \\
\hline
\end{tabular}

\section{Discussion}

This researcher revealed that, in terms of its usability and usefulness, the AmeeSehat app is feasible to future brides and grooms. Participants considered AmeeSehat beneficial because they had the opportunity to learn more about a stable home life in preparation for marriage. They also thought that AmeeSehat was simple to use and could enhance marital readiness and a healthy family relationship. The quantitative results have shown that many users have improved their awareness, attitude, and intent in advice for pre-marital care regarding the development of a good family life after using AmeeSehat. Participants thought that AmeeSehat was easy to use and easy to see. The SUS scoring also showed the usability of AmeeSehat.

Tackling the problem of healthy family relationships and healthy marriage is not a simple task and in terms of usability and usefulness, AmeeSehat had to be further developed. The main advantage was the inclusion of a new module for premarital education. Instead of preparing to live as a wife or husband, AmeeSehat also had to be posed in order to optimize health, as they usually do not see importance of a healthy marriage or family, but would like to understand more about maintaining health. Due to a lack of interest in a healthy family, AmeeSehat had to be modified and simplified to provide key messages as quickly as possible. Further efforts were needed for the future bride and groom to understand and accept the message to avoid unnecessary risky health behavior. These have been key to the development of future interventions by policymakers and researchers, particularly in areas surrounded by misunderstandings and of low public attention.

The results of this usability and usefulness may appear differently if AmeeSehat has been established as a mobile web app instead of a mobile app, which could be easier to access on your PC or mobile phone.
The research team has, however, decided to develop AmeeSehat for easy distribution in the form of a mobile app. Although this prevents AmeeSehat from having more effective functions, its a much more critical issue to reach out to the future bride and groom as a health mobile app or mobile web application is not really something the future bride and groom want, since they do not see the significance of the health marriage. A smartphone app is broader than a web app because it can be easily accessed and shared with friends instantly [23]. As in this paper, the prior study showed the significance of an iterative way of designing mHealth applications to identify end-user requirements and improve applicable feasibility [22], [23], [32]. The importance of performing usability tests in mHealth applications for use in clinical care settings therefore needs to be given considerable attention. User design is an important part of the development of mHealth applications, especially in the effective modification of the behavior of individual patients and/or their effect. This is a significant consideration for experts and researchers in public health, in particular when tackling problems of health which are not deemed publicly important.

The results of this study indicate that mobile applications, namely, AmeeSehat have potential benefits on improving knowledge, attitude, intention, and marriage readiness. Past studies have shown that mobile apps can increase knowledge, attitudes, and intentions effectively [32]. This marriage counseling service is very necessary to provide readiness for the prospective husband/wife to be able to build a happy and harmonious household. Self-readiness to get married is needed so that each partner can know, understand, and respond to the values of marriage which refer to the meaning and wisdom of marriage in family life. Furthermore, couples who did counseling before marriage tended to be more satisfied and committed in their marriage compared to couples who did not do counseling and their marriages ended in divorce [33]. The previous research reveals that the factors that influence psychological readiness for marital relationships have been identified, in particular attitudes, marital motives, weight of adaptive abilities, emotional and moral maturity, age of marriage, materiality, spouse status, and parental influence; it was found that $68.0 \%$ of the bride and groom were psychologically unprepared for the marital relationship [15]. Couples who have the readiness to live a married life will more easily accept and face all the consequences of problems that arise in marriage.

\section{Strengths and limitations}

This analysis includes many strengths and constraints. The strength of this research was that we were able to sample from a diverse demographic spectrum, contributing to the overall variations in the 
qualitative results. The multi-faceted approach (mixed method, analytical, and retrospective TA) allowed the study to collect a rich amount of data and to triangulate data. With regard to limitations, the nature of the usefulness section of the survey form restricted the analysis of the data. In addition, the major limitation is that TA sessions took place in a private room of public health services. It could have taken a bit longer for users to look carefully at the app once at home. This can also impact how users use AmeeSehat because, unlike in their homes, they may feel supervised and obligated to use AmeeSehat appropriately. Although the sample size for the SUS was adequate, as suggested by experts, for the usefulness of the question was insufficient, in particular, for the McNemar test of knowledge, attitude, intention, and readiness. However, the study focused primarily on qualitative results which defined problems in order to improve AmeeSehat. The quantitative results were only tentative findings of efficacy which are more definitely assessed in a sample.

\section{Conclusions}

This study has shown that AmeeSehat is acceptable to future bride and groom in terms of its usability and usefulness. Future bride and bride can learn more about healthy marriage and good family life through AmeeSehat. The preliminary data indicated that AmeeSehat could increase understanding, attitude, intention, and readiness to enhance their family health. Further assessment should be carried out in the form of a randomized controlled trial to test AmeeSehat's effectiveness in enhancing awareness, attitude, intention and readiness. In addition, the study allowed the improvement of the usability and usefulness of AmeeSehat. This study also shared valuable lessons from that beta test, which could be useful for the potential development of user-centered mobile applications by health experts and researchers.

\section{Availability of Data and Materials}

Data supporting the results of the current study is available on request from the corresponding author.

\section{Authors' Contributions}

ZW designed the study and recruited the participants. ZW, FO, and DD conducted data collection analyzed the data and wrote the manuscript. ZW, FO, and DD contributed to the design of the study, and manuscript writing. All authors contributed, read, and approved the final manuscript.

\section{References}

1. Murayama S. Regional standardization in the age at marriage: A comparative study of preindustrial Germany and Japan. Hist Fam. 2001;6:303-24.

2. Zarabi V, Mostafavi F. Measuring factors affecting marriage in women of the Iranian view economic. J Econ Study. 2012;4:33-64.

3. Hosseini $\mathrm{H}$, Gravnd M. Measuring factors affecting of behavior and attitudes women to marriage age in the city Kohdasht. Women Dev Polit J. 2014;11:101-18.

4. Sadr Al Ashrafi M, Shamkhani A, Yousefi Afrasfteh M. Investigate factors affecting in the easy marriage from the student's women view Payame Noor University Razan. J Cult Eng. 2013;69:86-101.

5. Lavner JA, Bradbury TN, Karney BR. Incremental change or initial differences? Testing two models of marital deterioration. J Fam Psychol. 2012;26(4):606-16. https://doi.org/10.1037/ a0029052

PMid:22709260

6. Komnas Perempuan. Komnas Perempuan's Annual Note Fact Sheet (CATAHUN) 2020 the Maze of Violence Against Women From Gang Rape to Femicide, Alarm for the State to Act Appropriately; 2020. Available from: https://www. komnasperempuan.go.id. [Last accessed on $2021 \mathrm{Feb} 10]$

7. Shahhosseini Z, Hamzehgardeshi Z, Souraki MK. The effects of premarital relationship enrichment programs on marriage strength: A narrative review article. J Nurs Midwifery Sci. 2014;1:62-72. https://doi.org/10.4103/2345-5756.231408

8. Stelzer K. Marriage education with Hispanic couples: Evaluation of a communication workshop. Fam Sci Rev. 2010;15:1-14.

9. Stanley SM, Amato PR, Johnson CA, Markman HJ. Premarital education, marital quality, and marital stability: Findings from a large, random household survey. J Fam Psychol. 2006;20(1):117-26. https://doi.org/10.1037/0893-3200.20.1.117 PMid:16569096

10. Duncan SF, Childs GR, Larson JH. Perceived helpfulness of four different types of marriage preparation interventions. Fam Relat. 2010;59:623-36. https://doi. org/10.1111/j.1741-3729.2010.00628.x

11. DeMaria R. Psychoeducation and enrichment: Clinical considerations for couple and family therapy. In: Sexton TL, Weeks GR, Robbins MS, editors. Handbook of Family Therapy. United Kingdom: Brunner-Routledge; 2003. p. 411-30.

12. Ramezankhani A, Mohammadi G, Akrami F, Ghanbari S, Alidousti FA. Quality gap in premarital education and consultation program in the health centers of Shahid Beheshti Medical University. Pajoohandeh J. 2011;16:169-77.

13. Yazdanpanah M, Eslami M, Nakhaee N. Effectiveness of the Premarital Education Programme in Iran, ISRN Public Health; 2014. p. 1-5. https://doi.org/10.1155/2014/964087

14. Ibrahim NK, Bashawri J, Al Bar H, Al Ahmadi J, Al Bar A Qadi $\mathrm{M}$, et al. Premarital Screening and genetic counseling program: Knowledge, attitude, and satisfaction of attendees of governmental outpatient clinics in Jeddah. J Infect Public Health. 2013;6(1):41-54. https://doi.org/10.1016/j.jiph.2012.05.001 


\section{PMid:23290092}

15. Denysenko A. Peculiarities of psychological readiness of adolescent girls for marital relationships. Herald Kiev Inst Bus Technol. 2020;43(1):75-81. https://doi.org/10.37203/ kibit.2020.43.11

16. Kemenkes RI. Regulation of the Minister of Health of the Republic of Indonesia Number 25 of 2014 Concerning Health Services for the Period Before Pregnancy, Pregnancy, Childbirth, and the Period after Childbirth, Implementation of Contraception Services, as Well as Sexual Health. Jakarta: Kemenkes RI; 2014.

17. Peraturan Direktur Jenderal Bimbingan Masyarakat Islam Nomor: DJ.II/542 Tahun 2013 About the Guidelines for Organizing Pre-Marriage Courses; 2013.

18. Erlyani N, Zwagery RV. Village pramarital counseling program (Koprade) to increase marriage readiness for potential partners in communities on the banks of the Martapura River, Banjar Regency. Proceedings of the National Land Environment Seminar Wet. 2018;3(2):525-30.

19. Oktalia J. Conscience Module use in Preconception Class for Prospective Quality Assurance for the Quality of Pregnancy Planning for Couples of Early Age. Jakarta: Poltekkes Jakarta Kemenkes RI; 2014.

20. Badawy SM, Kuhns LM. Texting and mobile phone app interventions for improving adherence to preventive behavior in adolescents: A systematic review. JMIR MHealth UHealth. 2017;5(4):e50. https://doi.org/10.2196/mhealth.6837

\section{PMid:28428157}

21. de la Vega R, Miró J. mHealth: A strategic field without a solid scientific soul. a systematic review of pain-related apps. PLoS One. 2014;9(7):e101312. https://doi.org/10.1371/journal. pone.0101312 PMid:24999983

22. Kumar S, Nilsen WJ, Abernethy A, Atienza A, Patrick K, Pavel M, et al. Mobile health technology evaluation: The mHealth evidence workshop. Am J Prev Med. 2013;45(2):228-36. PMid:23867031

23. Majeed-Ariss R, Baildam E, Campbell M, Chieng A, Fallon D, Hall A, et al. Apps and adolescents: A systematic review of adolescents' use of mobile phone and tablet apps that support personal management of their chronic or long-term physical conditions. J Med Internet Res. 2015;17(12):e287. https://doi. org/10.2196/jmir.5043

PMid:26701961

24. Jaspers MW. A comparison of usability methods for testing interactive health technologies: Methodological aspects and empirical evidence. Int J Med Inform. 2009;78(5):340-53. https:// doi.org/10.1016/j.ijmedinf.2008.10.002

PMid:19046928

25. Peute LW, de Keizer NF, Jaspers MW. The value of retrospective and concurrent think aloud in formative usability testing of a physician data query tool. J Biomed Inform. 2015;55:1-10. https://doi.org/10.1016/j.jbi.2015.02.006

PMid:25733166

26. Overdijkink SB, Velu AV, Rosman AN, van Beukering MD, Kok M, Steegers-Theunissen RP. The usability and effectiveness of mobile health technology-based lifestyle and medical intervention apps supporting health care during pregnancy: Systematic review. JMIR MHealth UHealth. 2018;6(4):e109. https://doi.org/10.2196/mhealth.8834

PMid:29691216

27. Bandura A. Social Cognitive Theory and Exercise of Contro Over HIV Infection, Preventing AIDS; 1996. p. 25-59. https://doi. org/10.1007/978-1-4899-1193-3_3

28. Ericsson KA, Simon HA. Verbal reports as data. Psychol Rev. 1980;87(3):215-51.

29. Brooke J. SUS-a quick and dirty usability scale. In: Jordan PW Thomas B, Weerdmeester BA, McClelland IL, editors. Usability Evaluation in Industry. London: Taylor and Francis; 1996. p. 4-7. https://doi.org/10.1201/9781498710411-35

30. Nielsen J. Usability Engineering. United States: Morgan Kaufmann; 1994.

31. Bangor A, Kortum P, Miller J. Determining what individual SUS scores mean: Adding an adjective rating scale. J Usability Stud. 2009;4(3):114-23. Available from: http://www.uxpajournal. org/determining-what-individual-susscores-mean-adding-anadjective-rating-scale. [Last accessed on 2021 Feb 10].

32. Torkian S, Mostafavi F, Pirzadeh A. Effect of a mobile application intervention on knowledge, attitude and practice related to healthy marriage among youth in Iran. J Educ Health Promot. 2020;9:312. https://doi.org/10.21203/rs.2.22698/v1 PMid:33426116

33. Papalia DE. Experience Human Development. McGraw: Hil Education; 2014. 